\title{
Differences in the Meaning Between Handan County Dialect Vocabulary and Mandarin Vocabulary
}

\author{
Wang Xiaojun \\ Department of Uygur Language \& Culture, Northwest Minzu University, Lanzhou, China
}

Email address:

563826642@qq.com

To cite this article:

Wang Xiaojun. Differences in the Meaning Between Handan County Dialect Vocabulary and Mandarin Vocabulary. Humanities and Social Sciences. Vol. 5, No. 4, 2017, pp. 155-157. doi: 10.11648/j.hss.20170504.15

Received: July 3, 2017; Accepted: August 3, 2017; Published: August 17, 2017

\begin{abstract}
In terms of meaning, through the comparison of the words with the same form in Handan dialect vocabulary and mandarin, it is found that the difference is mainly manifested in the three aspects----lexical meaning, grammatical meaning and colorful meaning. Some words are with the same form, Handan County dialect words and mandarin words contain exactly the same or not exactly the same meaning, which embodies the Handan dialect vocabulary special expression. In the aspect of grammatical meaning, there are some differences in the concurrence and collocation of words between Handan dialect and mandarin, which enriches the vocabulary system of Handan dialect. In the aspect of color meaning, this article reflects the way people understand the things and the local customs and culture in Handan County from the difference of appraise, style and image.
\end{abstract}

Keywords: Vocabulary, Handan Dialect, Mandarin, Lexical Meaning, Grammatical Meaning, Colorful Meaning

\section{Introduction}

The difference in terms of meaning is an important aspect of the difference between dialect and Mandarin. "The meaning item is the subroutine of the lexical meaning of the word. The meaning of a word can not only summarize a certain kind of reality phenomenon, but also summarize the relationship between the several types of reality." [1]

"Handan County is located in the south of Hebei Province, and the east of Taihang Mountains. Handan County belongs to Handan City, which is a typical suburban county. Handan City is surrounded by Handan County. The content of this paper is the in the Meaning Between Handan County Dialect Vocabulary and Mandarin Vocabulary." [2]

From the "Handan dialect vocabulary Table ", we can see that many of the dialect vocabulary in Handan County can find the corresponding words in Mandarin, some of which has the same form of Mandarin, but the meaning is different. "Generally speaking, the meaning of words, including three parts----lexical meaning, grammatical meaning and color meaning." [3] I compared Handan dialect vocabulary and Mandarin vocabulary from these three aspects.

\section{Difference in Lexical Meaning}

There are some words in the dialect of Handan County, although their names are the same as those of Mandarin, but the meaning is different. The following mainly reveal the difference between Handan dialect vocabulary and Mandarin vocabulary in the lexical meaning from four aspects.

(1) Meaning is completely different

There are some words in the dialect of Handan County, which are the same as Mandarin in the form of words, but the meaning is completely different. These words are not crossed in terms of meaning. Here are some of these words, this paper compares their mandarin meaning and dialect meaning.

Table 1. Sample words with completely different meaning.

\begin{tabular}{lll}
\hline word & mandarin meaning & Handan County dialect meaning \\
\hline [ $\mathrm{s}^{`} \mathrm{u}$ ts'ai] & vegetables & spinach \\
[t'`on niæn] & adult & full year \\
[ər sai] & earplug & cerumen \\
[tcian] & coming soon & just a moment ago \\
\hline
\end{tabular}

In these words, although the meaning is completely different, but the inform is basically the same. In which the 
meaning of some words are different, but it has a certain relevance. Such as the word "[s'u ts'ai]" in Mandarin is the general term of vegetables, while in Handan County dialect refers to something concretely, which means "spinach". Such as "[ər sai]" in Mandarin and Handan dialect in the meaning of words are inseparable from the "ear" this sense of the element. Of course, there are some words in the sense of conflict, such as "[tciay]" in mandarin "coming soon" means the future time, and in the Handan dialect "just a moment ago" means the past time.

(2) Meaning in Handan dialect more than mandarin

Meaning in Handan dialect more than mandarin, that is, the meaning of the same word in Handan County dialect have more than one, but Mandarin only has one part.
Table 2. Sample words with more meaning in county dialect.

\begin{tabular}{|c|c|}
\hline Mandarin Word & More meaning in Handan County dialect \\
\hline $\begin{array}{l}{\left[\mathrm{s}^{6} \mathrm{q}\right]} \\
{\left[\mathrm{f}^{6} \mathrm{ei}\right]}\end{array}$ & $\begin{array}{l}\text { tired } \\
\text { naughty }\end{array}$ \\
\hline$\left[\mathrm{t}^{\mathrm{c}} \mathrm{au}\right]$ & $\begin{array}{l}\text { Put the cotton, silk and other flat into the bedding or } \\
\text { jacket in the sewn good. }\end{array}$ \\
\hline [t6ye] & shout abuse \\
\hline [bi ts] $]$ & snivel \\
\hline [tci tan] & zero points \\
\hline [tc'i lai $]$ & get up \\
\hline [tsau xu] & call \\
\hline
\end{tabular}

(3) Meaning in mandarin more than Handan dialect

Meaning in mandarin more than Handan dialect, that is, Handan dialect only use parts of the meaning in mandarin with the same word, the other meaning in Handan dialect has other words to express.

Table 3. Sample words with more meaning in mandarin.

\begin{tabular}{|c|c|c|}
\hline Mandarin Word & Analysis of mandarin meaning & Analysis of Handan dialect meaning \\
\hline \multirow{2}{*}{ [xuy] } & A. trick (v.) & \multirow{2}{*}{ Only has A, and use "[tou r]", "[tou tou]" to express B } \\
\hline & B. $\operatorname{coax}(\mathrm{n})$. & \\
\hline \multirow{2}{*}{$\mathrm{s}^{\prime}$ วy t6'i] } & A. get angry (v.) & \multirow{2}{*}{ Only has A, and use "[ts'u may]", "[tai tcin]" to express B } \\
\hline & B. vitality (n.) & \\
\hline \multirow{2}{*}{ [ti] } & A. land (n.) & \multirow{2}{*}{ Only has B, and use "[ti b" i]", "[f'ay tei ti]" to express A } \\
\hline & B. farmland (n.) & \\
\hline \multirow{3}{*}[\mathrm{xu}]{} & A. pot for boiling water & \multirow{3}{*}{ Only has A, and use "[s'uei xu]" to express B, and use "[nuan xu]" o express C } \\
\hline & B. pot filled with water use & \\
\hline & C. thermos bottle & \\
\hline
\end{tabular}

\section{Difference in Grammatical Meaning}

"The grammatical meaning of the word is the meaning of the grammatical function of the word. The grammatical meaning of the word is shown by the class after it is gathered, so it is a more abstract and more general meaning." [4] From the perspective of grammatical meaning of the corresponding Handan dialect and Mandarin words for comparative analysis, there are differences between these words. "The difference in grammatical meaning is the difference in the grammatical functions of the word. There are two types ---- concurrence and combination." [5] The following mainly analyzes the difference in grammatical meaning from the two aspects.

\subsection{Concurrence of Word}

"The difference in grammatical meaning is often manifested as the concurrence of word." [6] The word concurrence refers to a word often has two or several types main grammar function of words. There are a lot of concurrence words in modern Chinese, and there are such phenomena in the dialect of Handan County. Some of them are different from Mandarin in the concurrence of words. For example:
Table 4. Sample words with different concurrence.

\begin{tabular}{|c|c|c|}
\hline Mandarin Word & $\begin{array}{l}\text { Part of speech in } \\
\text { Mandarin }\end{array}$ & $\begin{array}{l}\text { Part of speech in } \\
\text { Handan dialect }\end{array}$ \\
\hline [k'ou] & A.v. (dig out) & $\begin{array}{l}\text { A.v. } \\
\text { B.a. (stingy) }\end{array}$ \\
\hline$[\mathrm{u}]$ & A.v. (cover) & $\begin{array}{l}\text { A.v. } \\
\text { B.a. (sultry) }\end{array}$ \\
\hline [miæn] & A.n. (cotton) & $\begin{array}{l}\text { A.n. } \\
\text { B.a. (soft taste) }\end{array}$ \\
\hline [ic] & A.a. (wild) & $\begin{array}{l}\text { A.a } \\
\text { B.v. (disport outside) }\end{array}$ \\
\hline [miæn] & $\begin{array}{l}\text { A.n. (flour) } \\
\text { B.q. }\end{array}$ & $\begin{array}{l}\text { A.n. } \\
\text { B.q. } \\
\text { C.a. (soft taste) }\end{array}$ \\
\hline [zou] & A.n. (meat) & $\begin{array}{l}\text { A.n. } \\
\text { B.a. (slow personality) }\end{array}$ \\
\hline [bau siæn] & A.n. (insurance) & A.n. \\
\hline
\end{tabular}

\subsection{Collocation of Word}

Zhu Yue in the "semantic theory" says that "whether a word with another word with the semantic features of the word has an important link. Each word has its relatively stable semantic feature library. This semantic feature library includes grammatical semantic features, rational semantic features, and rational semantics when used, which determine whether a word that combined with another word is a combination of conventional or unconventional." [7] There are some words in Handan dialect with another word that is a combination of 
anti-conventional, that is to say some words with the sense of a difference in the Mandarin. For example:

Table 5. Sample words with different collocation.

\begin{tabular}{|c|c|c|}
\hline Mandarin Word & Collocation in Mandarin (conventional) & Collocation in Handan dialect (unconventional) \\
\hline & [cia s'an] (go down the mountain) & [cia nai] (promote lactation) \\
\hline [cia] (down from a height) & [cia y] (rain) & [cia cyc] (leave school) \\
\hline [p'i] (mark) & [p'i kuy s'] (mark document) & [p'i ba tsir] (tell fortune with birthday) \\
\hline [te'?] (eat) & $\begin{array}{l}\text { [ts'? f'an] (have a meal) } \\
\text { [ts'? nai] (suck) }\end{array}$ & [ts'? xuei lu] (take bribes) \\
\hline
\end{tabular}

\section{Difference in Color Meaning}

The color meaning is the meaning of a certain tendency or mood expressed by the word, which is attached to the rationality of the word to express the specific feelings given by the person or context. The color meaning of the word contains three aspects: emotional color, style color, image color.

\subsection{Difference in Emotional Color}

"The emotional meaning of a word is the meaning of expressing the emotional attitude of the speaker on the basis of its rational meaning" [8] Some words in the Mandarin is a neutral word or with a commendable color, but in Handan County dialect with a derogatory color. For example, "can" in Mandarin refers to "capable, talented", which is a commendatory word. In Handan County dialect, you can also say "strong performance" with derogatory.

\subsection{Difference in Style Color}

"Style color refers to that the words has the meaning to adapt to a particular language style." [9] For the sick, the scourge and the sex of men and women, and so on. Such as people do not want or inconvenient to express things directly, Handan dialects usually use euphemistic expression, reflecting their own style of color. There are many this kind of word in Handan County dialect. The following will give a few typical examples. For example: for the expression of "death", Handan dialect generally use "[kuo s'i], [t6'y s'i], [ts'i s'i], [6iع s'i]" and so on in the serious, solemn occasion, and "[mei

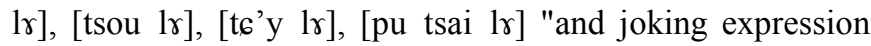

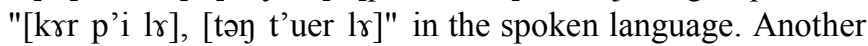
example is "pregnancy", in Handan County dialect more

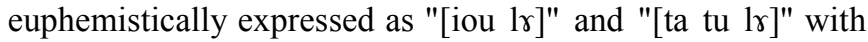
irony. In some taboo occasions, Handan dialect called "pregnant women" as "[si iæn rən]".

\subsection{Difference in Image Color}

"Words effect on the people's senses and cause association from a certain image is the image color." [10] There are many words in Handan County dialect with image color, which will give people an intuitive feeling, and highlight the characteristics of things. For example, Handan County dialect named things according to the dynamic such as [tciau ly] (jackass), [tcic tau] (kitchen knife), [p'u təy r] (Light moth) and so on, and named things according to the form such as [sau tsou cin] (comet), [ts'an ts'un] (snake) and so on.

\section{Conclusion}

In terms of meaning, through the comparison of the words with the same form in Handan dialect vocabulary and mandarin, it is found that the difference is mainly manifested in the three aspects----lexical meaning, grammatical meaning and colorful meaning. Some words are with the same form, Handan County dialect words and mandarin words contain exactly the same or not exactly the same meaning, which embodies the Handan dialect vocabulary special expression. In the aspect of grammatical meaning, there are some differences in the concurrence and collocation of words between Handan dialect and mandarin, which enriches the vocabulary system of Handan dialect. In the aspect of color meaning, this article reflects the way people understand the things and the local customs and culture in Handan County from the difference of appraise, style and image.

Because of the limited ability of the author, this paper only makes a simple comparative analysis and a lot of local research is not deep. These will continue to be explored and studied in future research.

\section{References}

[1] Ye Misheng, Xu Tongqiang. Linguistics Outline [M]. Beijing: Peking University Press, 2010.

[2] Journal of Shandong Normal University (Humanities and Social Sciences), 2002, No. 1 (in Chinese) [J]. Journal of Shandong Normal University (Humanities and Social Sciences), 2002.

[3] Li Rulong. Discussion on Vocabulary Differences in Chinese Dialects [J]. Chinese Language Research, 1982.

[4] Li Rulong. Chinese dialectology [M].

[5] Zhu Yue. Semantic Theory [M]. Peking University Press, 2006

[6] Li Rulong. Chinese dialectology [M]. Beijing: Higher Education Press, 2001.

[7] Zhu Yue. Semantic Theory [M]. Peking University Press, 2006.

[8] Dai Zhaoming. Modern Chinese lexicology [M]. Special teaching materials of Master's degree course, not published, 2011.

[9] Xing Fuyi. Wang Guosheng, Modern Chinese [M]. Huazhong Normal University Press, 2011.

[10] Huang Borong, Liao Xudong. Modern Chinese [M]. Beijing: Higher Education Press, 2011. 